\title{
Genişlemiş spektrumlu beta-laktamaz üreten E. coli izolatlarının çeşitli antibiyotiklere duyarlılıklarının belirlenmesi
}

\section{Determinating of susceptibilities to various antibiotic of the extended spectrum beta-lactamase producing E. coli isolates}

\author{
Fatih OCAK ${ }^{1}$, Atilla ÇiFCi2 ${ }^{2}$, Salih CESUR $^{*}$, Sami KINIKLI ${ }^{3}$
}

${ }^{1} Y$ ıldırım Beyazıt Üniversitesi, Yenimahalle Eğitim ve Araştırma Hastanesi, Mikrobiyoloji Laboratuvarı, Ankara/TÜRKiYE ${ }^{2}$ Yıldııım Beyazıt Üniversitesi, Yenimahalle Eğitim ve Araştırma Hastanesi, Çocuk Sağlığı ve Hastalıkları Anabilim Dalı, Ankara/TÜRKiYE ${ }^{3}$ Ankara Eğitim ve Araştırma Hastanesi, Enfeksiyon Hastalıkları ve Klinik Mikrobiyoloji Kliniği, Ankara/TÜRKIYE

\section{Öz}

Amaç: Genişlemiş spektrumlu beta-laktamaz (GSBL) enzimi üretimi ile beta-laktam antibiyotiklere direnç gelişmesi E.coli ve Klebsiella species ( Klebsiella spp.) suşlarında en sık görülen direnç mekanizmasıdır. GBSL üreten E. coli ve Klebsiella spp. neden olduğu enfeksiyonların tedavisinde son yıllarda temosilin ve fosfomisin de kullanılmaktadır. Bu çalışmanın amacı, çeşitli klinik örneklerden izole edilen ve GSBL üreten E. coli izolatlarının; temosilin, fosfomisin, ertapenem, imipenem, meropenem ve piperasilin-tazobaktam duyarlııklarının olarak disk difüzyon yöntemiyle belirlenmesidir

Gereç ve Yöntemler: Çalışmaya Ankara Yıldırım Beyazıt Üniversitesi Yenimahalle Eğitim ve Araştırma Hastanesi Mikrobiyoloji Laboratuvarı'nda çeşitli klinik örneklerden izole edilen ve genişlemiş spektrumlu beta laktamaz (GSBL) ürettiği çift disk sinerji yöntemiyle belirlenen $80 \mathrm{E}$. coli suşu dahil edildi. Suşların; temosilin, fosfomisin, ertapenem, imipenem, meropenem ve piperasilin-tazobaktam duyarlııkları disk difüzyon yöntemiyle CLSI önerileri doğrultusunda belirlendi.

Bulgular: Çalışmaya dâhil edilen GSBL üreten E. coli suşlarında antibiyotik duyarlılık oranları sırasıyla; ertapenem \%100 (80/80), imipenem \%100 (80/80), meropenem \%100 (80/80), temosilin \%98,7 (79/80) , piperasilin-tazobaktam \%96 (77/80) ve fosfomisin \%95 (76/80) olarak belirlendi.

GSBL üreten E. coli suşlarında karbapenemlere (ertapenem, imipenem ve meropenem) direnç saptanmadı.

Sonuç: Hastanemizde GSBL üreten E. coli suşlarında temosilin ve fosfomisin duyarlıık oranlarının yüksek olduğu, temosilin ve fosfomisinin bu etkenlere bağlı enfeksiyonların tedavisinde karbapenemlere alternatif ilaçlar olarak kullanılabileceği belirlendi.

Anahtar Kelimeler: Genişlemiş spektrumlu beta-laktamaz; E. coli; antibiyotik duyarlıı̆ı̆; disk difüzyon yöntemi; temosilin; fosfomisin 


\begin{abstract}
Aim: Production of extended-spectrum beta-lactamase (ESBL) enzymes are the most common resistance mechanism against beta-lactam antibiotics on E. coli and Klebsiella spp. Temocillin and fosfomycin have also been used in the treatment of infections caused by ESBL producing E. coli and Klebsiella spp. The aim of this prospective study is to determine the susceptibility of temocillin, fosfomycin, ertapenem, imipenem, meropenem, and piperacillin-tazobactam to ESBL-producing E. coli isolate isolated from various clinical samples by the disk diffusion method.
\end{abstract}

Material and Methods: The study included $80 \mathrm{E}$. coli strains isolated from various clinical samples in Ankara Yıldırım Beyazit University Yenimahalle Training and Research Hospital, Microbiology Laboratory and ESBL producing were determined by double disc synergy method. The susceptibilities of the strains to temocillin, fosfomycin, ertapenem, imipenem, meropenem, and piperacillin-tazobactam were determined according to the CLSI recommendations by disk diffusion method. Determined by double disc synergy method. The susceptibilities of the strains to temocillin, fosfomycin, ertapenem, imipenem, meropenem, and piperacillin-tazobactam were determined according to the CLSI recommendations by disk diffusion method.

Results: The antibiotic susceptibility rates of ESBL-producing E. coli strains included in the study were as follows; ertapenem $100 \%(80 / 80)$, imipenem 100\% (80/80), meropenem 100\% (80/80), temocillin 98.7\% (79/80), piperacillin-tazobactam 96\% $(77 / 80)$ and fosfomycin $95 \%$ (76/80).

Conclusion: Sensitivity of ESBL-producing E. coli strains against temocillin and fosfomycin were found to be high in our hospital. It has been determined that temocillin and fosfomycin can be used as alternative drugs to carbapenems in the treatment of infections due to these agents.

Keywords: Extended spectrum beta-lactamase; E. coli; antibiotic susceptibility; disc-diffusion method; temocillin; fosfomycin

\section{Giriş}

Genişlemiş spektrumlu beta-laktamaz (GSBL) üreten Enterobacteriaceae ailesi üyeleri sıklıkla sağlık bakımıla ilişkili enfeksiyonlara neden olmaktadırlar. Bununla birlikte GSBL üreten mikroorganizmalarla oluşan toplum kaynaklı enfeksiyonlar da bildirilmektedir. GSBL üreten Escherichia coli (E. coli) ve Klebsiella spp. suşlarının neden olduğu enfeksiyonların tedavisi güçtür ve tedavide sıklıkla karbapenemler kullanılmaktadır [1]. Ayrıca son yıllarda karbapenemlere dirençli E. coli ve Klebsiella spp. suşları da bildirilmektedir [2]. Bu nedenle tedavide karbapenemler dışındaki antibiyotikler de gündeme gelmiştir. GSBL üreten E. coli ve Klebsiella spp. enfeksiyonlarında karbapenemlere alternatif antibiyotikler içerisinde, temosilin ve fosfomisin yer almaktadır. Bu çalışmada GSBL üreten E. coli suşlarının temosilin, fosfomisin,karbapenemler (imipenem, meropenem ve ertapenem) ve piperasilin-tazobaktam duyarlııklarının belirlenmesi amaçlandı.

\section{Gereç ve Yöntemler}

Çalışmaya 2018 yııında Ankara Yıldırım Beyazıt Üniversitesi Yenimahalle Eğitim ve Araştırma Hastanesi, Mikrobiyoloji
Laboratuvarı'nda çeşitli klinik örneklerden izole edilen ve çift disk sinerji yöntemiyle GSBL pozitif saptanan $80 \mathrm{E}$. coli suşu dahil edildi. Suşların tanımlanması konvansiyonel yöntemler ve otomatize identifikasyon sistemleri kullanılarak yapıldı. Suşların izole edildiği klinik örneklerin dağılımı aşağıdaki Tabloda gösterilmiştir. Retrospektif çalışma kurum onayı alınmıştır. Hastalardan aydınlatılmış onam formları alınmıştır.

\begin{tabular}{lc}
$\begin{array}{l}\text { Tablo. E.coli suşlarının izole edildiği klinik örneklerin } \\
\text { dağıımı (n:80) }\end{array}$ \\
Örnek türü & Sayı $(\%)$ \\
\hline İdrar & $70(87,5)$ \\
Kan & $2(2,5)$ \\
Balgam & $2(2,5)$ \\
Derin trakeal aspirat (DTA) & $2(2,5)$ \\
Yara & $2(2,5)$ \\
Boğaz sürüntüsü & $1(1,2)$ \\
Vajinal akıntı & $1(1,2)$ \\
Toplam & $80(100)$
\end{tabular}

\section{Çift disk sinerji testi}

Mc Farland 0,5 standardı yoğunluğunda olacak şekilde hazırlanan bakteri süspansiyonu Mueller-Hinton agar (MHA) plağına yayıldı. Plağın ortasına bir amoksisilin-klavulanik asit diski (AMC 20/10 Mg) ile disk merkezleri arasındaki uzaklık 
$30 \mathrm{~mm}$. olacak şekilde seftazidim (CAZ), seftriakson (CRO) veya sefotaksim (CTX), aztreonam (ATM) diskleri yerleştirildi. Bir gece $35^{\circ} \mathrm{C}$ 'de inkübasyondan sonra sefalosporin veya ATM etrafındaki inhibisyon zonunun AMC diskine doğru genişlemesi veya arada bakterinin üremediği bir sinerji alanının bulunması GSBL varlığını olarak değerlendirildi [3].

Çalışmada, besiyeri ve disklerin kalite kontrolü ve doğrulanması amacıyla E. coli ATCC 25922 suşu standart suş olarak kullanıldı. İzole edilen suşların; temosillin, fosfomisin, ertapenem, imipenem, meropenem ve piperasilin-tazobaktam duyarlılıkları bu antibiyotiklerin emdirilmiş olduğu ticari diskler ile (BectonDickinson, USA) disk difüzyon yöntemiyle belirlendi. Suşların bu antibiyotiklere duyarlılıkları CLSI önerileri doğrultusunda belirlendi [4]. Temosilin için zon çapı $\geq 19-20 \mathrm{~mm}$ ise duyarlı, 16$18 \mathrm{~mm}$ ise orta duyarlı, $\leq 15 \mathrm{~mm}$ ise dirençli olarak kabul edildi $[5,6]$. Fosfomisin için zon çapı $\geq 16 \mathrm{~mm}$ ise duyarlı, $13-15 \mathrm{~mm}$ ise orta duyarlı, $\leq 12 \mathrm{~mm}$ ise dirençli olarak kabul edildi [4]. Elde edilen duyarlılık oranları \% olarak ifade edildi.

\section{Bulgular}

Sunduğumuz çalışmaya dâhil edilen E. coli suşlarının $\% 77,5^{\prime} u$ idrar örneklerinden, \%22,5'i ise idrar dışı örneklerden (kan, balgam, yara vb.) oluşmaktaydı. Çalışmaya dahil edilen $80 \mathrm{E}$. coli suşunun hepsinde GSBL varlığı çift disk sinerji yöntemi ile belirlendi. Çalışmamızda GSBL üreten E. coli suşlarında antibiyotik duyarlılıkları ise disk difüzyon yöntemiyle belirlendi. Çalışmaya dahil edilen GSBL üreten E. coli suşlarında antibiyotik duyarlılık oranları sırasıyla; ertapenem \%100 (80/80), imipenem \%100 (80/80) , meropenem \%100 (80/80), temosilin \%98,7 (79/80), piperasilin-tazobaktam \%96 ve fosfomisin \%95 olarak belirlendi. GSBL üreten E. coli suşlarında karbapenemlere (ertapenem, imipenem ve meropenem) direnç saptanmadı.

\section{Tartışma}

Enterobacteriaceae ailesi üyeleri içerisinde yer alan E. coli toplum ve hastane kaynaklı üriner sistem enfeksiyonlarına en sık neden olan etkendir $[7,8]$.

Enterobacteriaceae ailesi üyelerinde beta-laktam antibiyotiklere karşı en fazla bildirilen direnç mekanizması GSBL enzimi üretimidir. GSBL enzimi, 1., 2., 3. kuşak sefalosporinleri ve aztreonamı parçalayarak etkisiz hale getirirken, sefamisin grubu (sefoksitin, sefotetan) ve karbapenemlere karşı etkisizdir. GSBL enziminin etkileri klavulanik asitle inhibe olur. Hem hastane kaynaklı hem de toplum kaynaklı E. coli suşlarında, tüm dünyada ve ülkemizde artan direnç oranları bildirilmektedir $[9,10]$. Türkiye'de E. coli suşlarında bildirilen GSBL oranı \%42, Klebsiella pneumoniae (K. pneumoniae) suşlarında ise \%41,4 olarak bildirilmiştir [10].

GSBL üreten E. coli ve K. pneumoniae izolatlarının tedavisinde en sık kullanılan antibiyotikler karbapenemlerdir [11]. Bununla birlikte son yıllarda karbapenemlerin yaygın kullanımına bağlı olarak karbapenemlere dirençli E. coli ve K. pneumoniae enfeksiyonları sıklıkla bildirilmektedir [2]. Bu nedenle GSBL üreten Enterobacteriaceae ailesi üyelerinin tedavisinde karbapenemler dışındaki alternatif antibiyotiklere gereksinim vardır. $\mathrm{Bu}$ antibiyotikler içerisinde; piperasilin-tazobaktam,fosfomisin, temosilin ve kolistin yer almaktadır $[9,11,12]$.

Çalışmamızda GSBL pozitif E. Coli suşlarında karbapenemlere (imipenem, meropenem ve ertapenem) direnç saptanmazken, temosiline $\% 1,3$, piperasilin-tazobaktama \%4, fosfomisine ise $\% 5$ oranında direnç saptadık.

Ip ve ark. [9] Hong Kong'da yaptıkları bir çalışmada kan ve idrar kültüründen izole edilen 613 Enterobacteriaceae ailesi üyesinin duyarlılık oranlarını mikrodilüsyon yöntemiyle temosiline $\% 93$, ertapeneme $\% 99$, meropeneme $\% 99,7$, piperasilin-tazobaktama $\% 86$, siprofloksasine $\% 71,5$, nitrofurantoine $\% 76,4$ olarak, agar dilüsyon yöntemiyle ise fosfomisine duyarlılık oranını $\% 92,8$ olarak belirlemişlerdir. Aynı çalışmada GSBL pozitiflik oranı \%23,2 olarak belirlenirken, GSBL pozitif izolatlarda temosilin direnci \%16,1 olarak bildirilmiştir. Çalışmada temosilinin özellikle siprofloksasin, nitrofurantoin ve piperasilin-tazobaktama yüksek direnç nedeniyle GSBL üreten Enterobacteriaceae ailesi üyelerinin neden olduğu enfeksiyonlarının tedavisinde uygun bir seçenek olduğu bildirilmiştir.

Chen ve ark. [8] 155 çoklu ilaca dirençli E. coli ve K. pneumoniae suşunda temosilin duyarlılığını E. coli ve K. pneumoniae suşları için \%95, fosfomisin için ise sırasıyla; \%78 ve \%66 olarak belirlemişlerdir. Çalışmadaki suşlarda GSBL oranı \%30 olarak belirlenmiştir.

Çalışmamızda temosiline direnç oranının düşük $(\% 1,3)$ olmasının nedeni, ülkemizde temosilinin henüz kullanıma girmemiş olmasından kaynaklanabilir.

Çalışmamızın sınırlandırıcı yanları; izole edilen suşlarda maliyet nedeniyle temosilin, fosfomisin etken maddelerinin temin edilememesi, altın standart yöntem olan sıvı mikrodilüsyon yöntemiyle minimal inhibitör konsantrasyon (MiK) değerlerinin belirlenememiş olması ve temosilin için CLSI ve EUCAST tarafından 2018 yılı dokümanlarında disk difüzyon yöntemi için zon çaplarının henüz belirlenmemiş 
olmasıdır. Sunduğumuz çalışmada temosilin zon çapının değerlendirilmesinde bu konuda yapılmış çalışmalar referans olarak alınmıştır [5,6].

Zykov ve ark. (12) Norveç'te GSBL üreten 105 E. coli suşunda otomatize sistem veya MiK gradient test yöntemleriyle yaptıkları çalışmada, tüm izolatların fosfomisin, temosilin ve meropeneme duyarlı olduğunu bildirmişlerdir.

Fournier ve ark. [11] 100 GSBL üreten E. coli suşunda yaptıkları çalışmada, suşların \%90'ından fazlasını fosfomisine duyarlı saptadıklarını ve üriner sistem enfeksiyonlarında iyi bir oral tedavi seçeneği olduğunu bildirmişlerdir. Aynı çalışmada temosilin ve piperasilin-tazobaktamın ise kan akımı enfeksiyonları ve piyelonefrit için karbapenemlere alternatif etkili antibiyotikler olduğunu bildirmişlerdir.

Titelman ve ark. [13] GSBL üreten $159 \mathrm{E}$. coli suşunda yaptıkları çalışmada fosfomisin direnç oranını \%3, ertapenem için \%1, piperasilin-tazobaktam için \%9, temosilin içinse \%24 olarak bildirmişlerdir.

Sonuç olarak, GSBL üreten E. coli suşlarında temosilin ve fosfomisin duyarlılık oranlarının yüksek olduğu, temosilin ve fosfomisinin bu etkenlere bağlı enfeksiyonların tedavisinde karbapenemlere alternatif ilaçlar olarak kullanılabileceği belirlendi.

\section{Maddi Destek ve Çıkar illişkisi}

Çalışmayı maddi olarak destekleyen kişi/kuruluş yoktur ve yazarların herhangi bir çıkar dayalı ilişkisi yoktur.

\section{Kaynaklar}

1. Kuzucu Ç, Yetkin F, Görgeç S, Ersoy Y. Genişlemiş spektrumlu beta-laktamaz üreten Escherichia coli ve Klebsiella spp. suşlarının ertapenem ve diğer karbapenemlere karşı duyarlılıklarının araştırılması. Mikrobiyol Bül 2011; 45: 28-35.

2. Nordmann P. Carbapenemase-producing Enterobacteriaceae: overview of a major public health challenge. Med Mal Infect 2014; 44: 51-55

3. Paterson DL, Bonomo RA. Extended-spectrum beta-lactamases: a clinical update. Clin Microbiol Rev 2005; 18: 657-86.

4. Clinical and Laboratory Standards Institute. Performance standards for antimicrobial susceptibility testing. Twentieth Informational Supplement. Document M100-S20-U, 2010. CLSI, Wayne, PA.

5. Fuchs PC, Barry AL, Thornsberry C, Jones RN. Interpretive criteria for temocillin disk diffusion susceptibility testing. Eur J Clin Microbiol 1985; 4: 30-33.
6. Vanstone GL, Dilley R, Schwenk S, Williams A, Balakrishnan I. Temocillin disc diffusion susceptibility testing by EUCAST methodology. J Antimicrob Chemother 2013; 68: 2688-89.

7. Ullah F, Malik SA, Ahmed J. Antibiotic susceptibility pattern and ESBL prevalence in nosocomial Escherichia coli from urinary tract infections in Pakistan. African J Biotechnol 2009; 8: 3921-26

8. Chen YT, Murad KA, Ng LS, Seah JTH, Park JJ, Tan TY. In vitro efficacy of six alternative antibiotics against multidrug resistant Escherichia coli and Klebsiella pneumoniae from urinary tract infections. Ann Acad Med Singapore 2016; 45: 245-50.

9. Ip M, Lai CK, Fung KSC et al. Activity of temocillin and 15 other agents, including fosfomycin and colistin, against Enterobacteriaceae in Hong Kong. Eur J Clin Microbiol Infect Dis 2017; 36: 2491-94.

10. Gur D, Hascelik G, Aydın N et al. Antimicrobial resistance in Gramnegative hospital isolates: Results of Turkish HITIT-2 Surveillance Study of 2007. J Chemother 2009; 21: 383-89.

11. Fournier D, Chirouze C, Leroy J, et al. Alternatives to carbapenems in ESBL-producing Escherichia coli infections. Med Mal Infect 2013; 43: 62-66.

12. Zykov IN, Sundsfjord A, Småbrekke L, Samuelsen O. The antimicrobial activity of mecillinam, nitrofurantoin, temocillin and fosfomycin and comparative analysis of resistance patterns in a nationwide collection of ESBL-producing Escherichia coli in Norway 2010-2011. Infect Dis (Lond) 2016; 48: 99-107.

13. Titelman E, Iversen A, Kahlmeter G, Giske CG. Antimicrobial susceptibility to parenteral and oral agents in a largely polyclonal collection of CTX-M-14 and CTX-M-15-producing Escherichia coli and Klebsiella pneumoniae. APMIS 2011; 119: 853-63. 